\title{
ORACIÓN E IMAGEN DE DIOS, Mt 7,7-11
}

\section{Introducción}

El objetivo del presente estudio consiste en el análisis exegético de la perícopa formada por los vv. 7 al 11 del séptimo capítulo del evangelio de Mateo. Este breve texto, apenas setenta y cuatro palabras, es identificado generalmente como una enseñanza acerca de la oración. Sin embargo, el centro de nuestra atención, a medida que avanzamos en la lectura o la escucha, se va desplazando hacia la imagen de Dios que Jesús nos quiere transmitir: partiendo de una exhortación y reflexión acerca del pedir del creyente se llega a la presentación del modo en que el Padre sabe dar.

Tal desplazamiento se realiza a través de una secuencia argumentativa que parte de los imperativos iniciales, continúa con dos preguntas retóricas y desemboca en una declaración final que se afirma, a su vez, en una constatación del mundo de los oyentes.

Nos interesa entonces, en orden a realizar un aporte exegético, mostrar que ese desplazamiento constituye un verdadero giro temático, esto es, que el texto, aunque comienza con una invitación a los oyentes acerca del pedir, tiene por objetivo presentar una enseñanza teológica en relación con el comportamiento divino.

En orden a hacer evidente tal carga teológica del texto, intentaremos dos abordajes metodológicos del mismo. En primer lugar, a partir de los resultados del método histórico-crítico, presentaremos un primer comentario exegético general. En segundo lugar lo abordaremos desde otro punto de vista que nos permita profundizar en el camino de la argumentación que Mt propone, poniendo el foco de la atención en el indicado salto de la experiencia humana al comportamiento del Padre. 
En este sentido, las relativamente recientes investigaciones lingüísticas y literarias acerca del lenguaje metafórico nos ofrecen un instrumental apropiado y pertinente en orden a abordar el texto desde el análisis de las imágenes que nos son presentadas. Esto es así porque se ha ampliado notablemente la noción tradicional de metáfora, que la reducía a una función decorativa, sobre todo en el discurso poético ${ }^{1}$, para redefinirla no solo desde su función retórica, sino incluso como fenómeno cognitivo: hay lenguaje metafórico ya donde se piensa «algo en términos de otra cosa» ${ }^{2}$.

El paso de un ámbito ampliamente conocido de la experiencia humana como es el del comportamiento de un padre con sus hijos al de «vuestro Padre que está en los cielos» así como las imágenes incluidas en los imperativos y sus correspondientes promesas, nos animan a investigar desde esta noción amplia del lenguaje metafórico. Esto es así en la medida en que es propio de tal forma de expresión elucidar o iluminar desde una realidad accesible al oyente o lector otro sector de la realidad que excede o problematiza la comprensión.

«Yo soy un buen cristiano», hace decir Péguy a Dios ${ }^{3}$. La ironía de la expresión nos ayuda a entender también un aspecto que quizá esté presente en nuestro texto y que lo hace plenamente actual: a primera vista pareciera que Jesús apunta a desarmar la sospecha acerca de las motivaciones que Dios tendría respecto de los hombres y su destino. En efecto, él se dirige a unos hombres que, como tantos contemporáneos nuestros, juzgan a

1 Esta noción es la que predomina en las retóricas clásicas de los siglos XVı al $X I X$, que, por otra parte, si bien continúan a Aristóteles, no dejan sin embargo de reducirlo: «Esta riqueza de matices que Aristóteles atribuye a la metáfora se va perdiendo en las retóricas y poéticas que le siguen, en las que perdura la idea de que la metáfora es una forma elevada del lenguaje, un desvío del modo en que habitualmente se habla, y que esa forma alejada del habla común cumpliría una función decorativa, embellecedora del estilo, lo que se ha llamado "función ornamental" de la metáfora, que asocia lo bello con lo elevado y con lo extraño, por oposición a lo bajo y común» (M. DI STÉFANO, «La perspectiva retórica», en: M. DI STÉFANo (coord.), Metáforas en uso. Buenos Aires, Biblos, 2006, p. 13).

2 Ibid., p. 14. Daniel Bourguet, al iniciar un estudio de las metáforas en Jeremías, propone, por ejemplo, la siguiente definición, suficientemente precisa, de la metáfora: «El hecho de describir intencionalmente, de manera mediata o inmediata, una cosa en los términos de otra que se le parece y que pertenece a otra isotopía» (D. Bourguet, Des métaphores de Jérémie. Paris, Gabalda, 1987, p. 10). Menos técnica, pero quizá más verdadera, es la que propone Borges: «Metáfora es el contacto momentáneo de dos imágenes, no la metódica asimilación de dos cosas...» (J. L. Borges, Otras inquisiciones, Buenos Aires, Emecé, 1960, p. 59).

3 Ch. PÉguy, El misterio de los Santos Inocentes. Madrid, Encuentro, 1993, p. 26. 
Dios más severo, o mezquino, o distraído de lo que nosotros solemos serlo. También con ironía se puede entender nuestro texto, que, partiendo de la pequeña pero real bondad humana, nos anima a no poner límites a la bondad del Padre.

\section{Comentario exegético general}

Intentaremos, en primer lugar, ubicar nuestro texto en relación con su contexto, tanto respecto a la doctrina de Mt acerca del Padre como a las perícopas anteriores y posteriores. En segundo lugar analizaremos las tres binas de los vv. 7,7-8 en cuanto promesas sin una determinación específica y en su posible relación con las respuestas que Dios pueda dar a ellas.

En tercer lugar nos extenderemos en comentar las dos preguntas retóricas del v. 10 como transición hacia la afirmación final del v. 11. En cuanto a este último, finalmente, será necesario tener en cuenta particularmente el punto de partida humano de la comparación a minori ad maius, el punto de llegada que involucra la imagen de Dios Padre y la clave de la argumentación centrada en la expresión cuánto más.

\section{Contexto amplio: la doctrina acerca del Padre}

El evangelista ha tomado la perícopa de su versión de la fuente Q y apenas la ha modificado ${ }^{4}$. De esa misma fuente proviene buena parte del

${ }^{4}$ Asumimos la reconstrucción del texto $Q$ según J. M. RoBinson y OTROS, El documento $Q$ en griego y en español; con paralelos del evangelio de Marcos y del evangelio de Tomás. Salamanca, Sígueme, 2002, p. 140. Las modificaciones redaccionales que ha realizado Mateo se reducen, a nuestro parecer, a tres: 1) La supresión de la

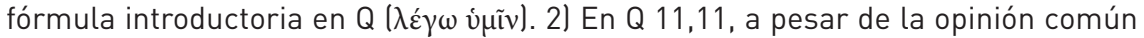
contraria, nos parece que es posible atribuir a Mateo el cambio de hombre por padre. Tres razones se suman para pensar así: al la preferencia de Mateo por esta

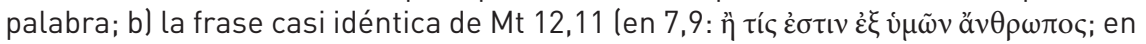

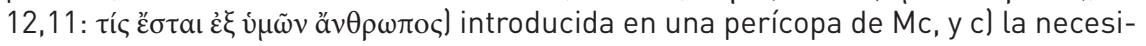
dad, en nuestro texto, de reservar el título de Padre para Dios. Teniendo en cuenta lo que se dirá respecto de las declaraciones teológicas acerca del Padre en el Sermón del monte, nos parece que atribuir esta modificación a Mateo es aún más pertinente. 3) Podemos decir con un gran margen de seguridad que Mateo ha mo-

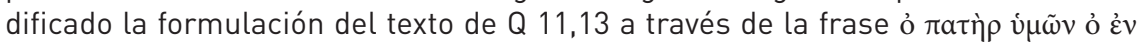
toĩ oủpavoĩc. Sin embargo quedan dudas al respecto: la expresión de Mt nunca más aparece tal cual en su evangelio y solo se encuentra en Mc 11,25. 
Sermón del monte, y Mateo mantiene la imagen de Jesús que al menos un importante estrato del Documento Q nos transmite y del cual forma parte nuestro texto: la de un maestro de sabiduría que centra su mensaje en el reino de Dios 5 .

Acorde con esta imagen es la presentación de los destinatarios del largo discurso elaborado por Mateo: ellos son tanto los discípulos como las multitudes (cf. Mt 4,25-5,1; 7,28-29).

Si bien nuestro texto aparece ubicado por el evangelista entre un conjunto de perícopas de temas variados, la importancia de su localización reside en que la frase final constituye, junto con otras revelaciones de Jesús en el Sermón del monte, una de las declaraciones teológicas con las cuales el Señor caracteriza la conducta y la actividad del Padre del cielo.

En efecto, para animar el amor a los enemigos se le había atribuido un amor igual «sobre malos y buenos», sobre «justos e injustos» $(5,45)$. En eso consiste la perfección del Padre (5,48; única declaración que utiliza el verbo ser $=\varepsilon i \mu \mathrm{l})$. Además, el Padre «ve en lo secreto» $(6,4.6 .18)$ y «sabe»lo que necesitan quienes se dirigen a él en la oración $(6,8)$. Perdonará a quienes perdonen $(6,14)$ y no lo hará a quienes no lo hagan $(6,15)$. Como base para animar a la despreocupación (seis veces en esta perícopa aparece «preocuparse» = $\mu \varepsilon \rho \mu \nu$ á $\omega:$ 6,25.27.28.31.34, con dos recurrencias en este último versículo) respecto de la comida y el vestido, Jesús declara que el Padre «alimenta» a las aves del cielo $(6,26)$, «viste» magníficamente a la hierba del campo $(6,30)$ y «sabe» que sus hijos necesitan todo aquello $(6,32)$.

A través de este apretado y bien enmarcado conjunto de declaraciones $^{6}$, tomadas en parte de Q $(5,45 ; 6,26.30 .32 ; 7,11)$, en parte de Mc $(6,14-15)$ y en parte del material propio $(6,4.6 .8 .18)$, Mateo ha delineado

${ }^{5}$ Creemos que Q 11,9-13 pertenece a un conjunto de textos que reflejan la enseñanza de Jesús como maestro de sabiduría más que como profeta escatológico. Mt ha tomado este texto, ubicado en su Vorlage, como parte de una colección de dichos caracterizados por formas sapienciales, y lo ha insertado en la parte final de su Sermón del monte. En esta última también ha ubicado otras perícopas con aquellas características (6,25-33; 7,1-5.16-20). Cf. R. A. PIPER, Wisdom in the Q-tradition. Cambridge, University Press, 1989, pp. 14-16.

6 Mateo incluye en su evangelio numerosas referencias al comportamiento del Padre o a sus atributos. La mayoría de estas declaraciones han sido ubicadas dentro de cuatro de los cinco grandes discursos de su evangelio. Entre las demás es central la declaración de Mt 11,25-27, que, a diferencia de todas las otras, se refiere a la relación del Padre con el hijo Jesús y, además, es la única que reúne varios verbos para caracterizar el comportamiento del Padre. En el Sermón del monte (primer discurso de $\mathrm{Mt}$ ) se incluyen diez referencias de este tipo: $5,45.48 ; 6,4.6 .8 .14-$ 15.18.26.32; 7,11. 
una coherente imagen del Padre «perfecto» que se compromete con su creación (plantas, animales), pero sobre todo con el hombre. Tal compromiso involucra además a todos los hombres, buenos y malos. Más aún, incluye una atención personal e íntima y abarca las relaciones mutuas de sus hijos de tal manera que el único don que el Padre puede negar en esta pequeña doctrina es su perdón para quien no perdone.

Por lo tanto, dentro del primer y principal discurso de Mt, nuestra perícopa ha sido ubicada de tal manera que cierra las declaraciones acerca del actuar del Padre con una promesa sin límites para quienes sepan pedirle «cosas buenas» $(7,11)$. Al mismo tiempo, su enseñanza enlaza con la primera declaración acerca del amor universal $(5,45)$ y encuentra su centro, como todo el conjunto doctrinal, en el Padrenuestro ${ }^{7}$.

\section{Contexto cercano}

Después de varias perícopas que comienzan con imperativos negati$\operatorname{vos}(6,25$ : «No andéis preocupados»; 7,1: «No juzguéis»; 7,6: «No deis a los perros lo que es santo»), con Mt 7,7 comienza una serie de pasajes con imperativos positivos (7,12: «Haced»; 7,13: «Entrad»; 7,15: «Guardaos»). A tres consejos o mandatos siguen tres sentencias. El tono es marcadamente sapiencial ${ }^{8}$.

A la pregunta acerca de una posible existencia independiente de $\mathrm{Mt}$ 7,7-8 nos parece necesario tener en cuenta que en $\mathrm{Q}$ ya aparece unido a 7,9$11 \mathrm{y}$, quizá más importante, la continuación responde justamente a la sorprendente indeterminación de los dos primeros versículos.

7 «Grundmann y Bornkamm son representativos de aquellos que ven la oración del Señor (6,9-13) como la clave de la disposición del Sermón» (C. H. TALBERT, Reading the Sermon on the Mount. Columbia, University of South Carolina, 2004, p. 21). En el mismo sentido afirma Luz que el Sermón del monte «aparece construido simétricamente alrededor de un centro, que es el Padrenuestro (6,9-13). Las secciones anteriores y posteriores al Padrenuestro se corresponden entre sí» (U. LUz, El Evangelio de Mateo I. Salamanca, Sígueme, 2001, p. 259).

8 «J. Schniewind vio ya que este logion suena como un proverbio. K. H. Rengstorf definió ya exactamente el Sitz im Leben (la "situación original") de la primera línea: es sabiduría de mendigos. "Mirad a los mendigos", dice Jesús, "lo porfiados que son, y que no se dan por vencidos cuando la gente los quiere rechazar: saben que la tenacidad conduce al éxito. Así de constante debe ser vuestra oración. Y tan segura debe estar de ser escuchada"» (J. JeREmiAS, Teología del Nuevo Testamento I. Salamanca, Sígueme, 1980, pp. 226-227). 


\subsection{Primera parte: $7,7-8$}

${ }^{7}$ Pedid y se os dará; buscad y hallaréis; llamad y se os abrirá. ${ }^{8}$ Porque todo el que pide recibe; el que busca, encuentra; y al que llama, se le abrirá.

\subsubsection{Promesa sin límite}

Lo que en primer lugar llama la atención es la indeterminación de los tres imperativos (pedid, buscad, llamad), expresada a través de la ausencia de objetos directos o de adverbios que caractericen las acciones. Más llamativo aún es que a los tres verbos en imperativo sucedan tres promesas en futuro también sin determinación. Es decir, Jesús promete sin poner ningún límite.

La fuerza del texto reside, pues, en tal indeterminación. Pero no debe dejar de notarse que en el mismo Sermón del monte Mateo ha incluido su versión del Padrenuestro, en la que se contiene el pedido de que el Padre dé «el pan cotidiano» $(6,11)$ y que «buscad», en imperativo presente, aparece idéntico en 6,33 respecto del «reino y su justicia».

Dado que estos verbos ya han aparecido con objetos directos, resulta más llamativo que en 7,7-8 carezcan de ellos.

Pensamos entonces que el v. 8 , al retomar los tres primeros verbos y repetirlos en forma de participio presente, no solo confirma las promesas, sino que comienza a trasladar el acento desde la acción del que pide, busca o llama a la de quien responde.

\subsubsection{Relación con Dios}

Respecto de la pregunta acerca de si la primera bina (pedir / dar o recibir) limita su sentido a la relación con Dios, y particularmente en cuanto a la oración, deben considerarse varios aspectos.

Por un lado, en el mismo Sermón del monte, Jesús pronuncia el verbo pedir en una sentencia inmediatamente anterior al Padrenuestro: «Vuestro Padre sabe lo que necesitáis antes de pedírselo [aĩñoal]» (Mt 6,8).

Tal uso de pedir invita a que nuestro texto sea interpretado como parte de las instrucciones de Jesús acerca de la oración. Sin embargo, además de que debe tenerse en cuenta que Mt 7,7-11 no está ubicado en la breve composición acerca de la oración de Mt 6,5-13, se ha de considerar que las siguientes dos binas (buscar / encontrar y llamar / abrir) 
parecen exceder ese marco e incluir al menos la búsqueda del «reino y su justicia» (Mt 6,33) .

Por otra parte, en el Antiguo Testamento solo al Rey Mesías se le anima a pedir a través de imperativos, con la seguridad de que YHWH dará sus dones ${ }^{10}$. No debe descartarse entonces que al menos Mateo (y quizá también Q) quiera transferir este trato privilegiado a los humildes oyentes, que en el Sermón del monte están llamados «a ser hijos de vuestro Padre celestial» (Mt 5,45).

En cuanto a la tercera bina, perfectamente enmarcable dentro de la relación con Dios, aporta a su vez un aspecto ya presente en Cant $5,2^{11} \mathrm{y}$ que se refuerza con el uso mateano de abrir en 25,11 y, aun sin coincidencias de vocabulario, con el imperativo de entrar «por la puerta estrecha» en el mismo Sermón del monte, pocos versículos después de nuestro texto (Mt 7,13).

Este aspecto de la relación con Dios incluye en el texto del Cantar la búsqueda amorosa que en la parábola mateana de 25,1-12 queda sin duda aludida. Llamar y abrir, por tanto, relacionados con los textos citados y con la

9 En el Padrenuestro se le pide al Padre que venga su Reino (Mt 6,10).

${ }^{10}$ En el sueño de Gabaón, yhwh ordena breve y perentoriamente: «Pídeme

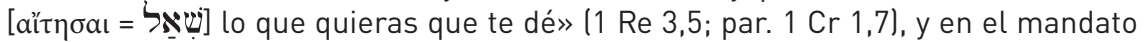
de pedir está implícita la seguridad de la respuesta. A tal punto es así que en el v. 13 se repetirá la bina en la respuesta de YHWH al rey: «También te doy lo que no has pedido». El mandato se repite exactamente en el Sal 2,8, esta vez al Rey-Mesías:

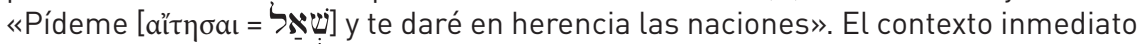
(v. 7) alude a la relación padre-hijo que involucra también la figura del rey Salomón a través del oráculo mesiánico de 2 Sam 7,13-14. En otro salmo mesiánico recurre la misma bina: «Vida te pidió y se la diste» (Sal 21,5). El texto bien puede relacionarse con la curación del rey Ezequías (2 Re 20,1-7; Is 38,1-20), pero también se refiere al final del sueño de Gabaón (1 Re 3,14). Se puede concluir que los tres textos están relacionados en cuanto a que es privilegio del rey, y particularmente del Rey-Mesías, el trato que yhwh dispensa, animando a través de imperativos a pedir gracias y otorgando la seguridad de recibirlas. Tal dignidad, sin embargo, se fundamenta en el don previo de la filiación divina

11 La bina llamar-abrir aparece en el AT únicamente en Cant 5,2. El verbo lla-

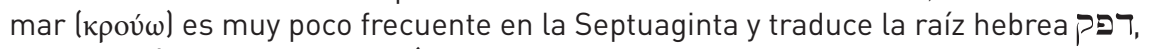
que también apenas recurre (Jue 19,22; Jdt 14,14; Cant 5,2; Gn 33,13, pero con el sentido de «ajetrear»). El solitario texto del Cantar es, sin embargo, de gran importancia en la medida que nos hace salir del campo semántico al que el texto de Mt nos parece llevar con sus tres binas, en cuanto a referencias veterotestamentarias, sea el de la petición o búsqueda de Dios, sea el de la referencia a la mendicidad o de las actividades cotidianas. En el Cantar entramos en el mundo de las relaciones afectivas en cuanto que abrir la puerta depende de un movimiento voluntario y no forzado del amante. 
segunda bina (buscar / encontrar) exceden entonces el marco estricto de la oración para ampliar su significado a la relación con Dios, su reino y su justicia.

\subsection{Segunda parte: 7,9-11}

${ }^{9}$ ¿O hay acaso alguno entre vosotros que al hijo que le pide pan le dé una piedra; ${ }^{10} 0$ si le pide un pez le dé una culebra? ${ }^{11} \mathrm{Si}$, pues, vosotros, siendo malos, sabéis dar cosas buenas a vuestros hijos, ¡cuánto más vuestro Padre que está en los cielos dará cosas buenas a los que se las pidan!

\subsubsection{Transición}

Los vv. 9-10 constituyen una transición entre las certezas de los vv. 7-8 y la argumentación del v. 11: a través de dos preguntas retóricas ${ }^{12}$, Jesús retoma el verbo pedir, aunque la respuesta aparece con un compuesto de $d a r^{13}$ que no cambia esencialmente el sentido. Las dos binas restantes no volverán a ser retomadas, lo cual en principio debe entenderse, teniendo en cuenta la estructura unitaria de todo el texto, en el sentido de que la segunda parte es también respuesta y explicación de lo que ellas significan.

\subsubsection{Preguntas retóricas}

En la primera pregunta, Mateo quizá ha modificado el texto de Q sustituyendo padre por hombre para reservar la referencia al Padre con más fuerza.

12 En las palabras de Jesús según Mateo encontramos frecuentemente este tipo de preguntas: $5,13.46-47 ; 6,25-28.31 ; 7,3-4.16 .22 ; 8,26 ; 9,4-5.15 ; 10,29 ; 11,7-$ 9.16.23; 12,4-5.11.26-27.29.34.48; 14,31; 15,3.16-17; 16,8-11.26; 17,17; 18,12.33; $19,4-5.17 ; 20,13.15 ; 21,16.28 ; 22,18.31-32.43-45 ; 23,19.33 ; 24,2.45 ; 26,10.40 .53-55$; 27,46 . Se presentan tanto en enseñanzas a la multitud o a los discípulos como en diálogos con estos últimos o con diversos adversarios en contexto claramente polémico. El ejemplo de 22,43-45, en el que Jesús lanza preguntas sin respuesta de sus interlocutores, es quizá el más expresivo para mostrar que la función de las preguntas retóricas es afirmar con énfasis un aserto innegable: justamente Mateo nos informa de que a esas inquisiciones «ninguno fue capaz de responderle una sola palabra» (Mt 22,46).

${ }^{13} \dot{\varepsilon} \pi \mathbf{\delta} \delta \hat{\delta} \delta \omega \mu$, que puede incluir un matiz más personal: «entregar en las manos de alguien» (H. K. Moulton, The Analytical Greek Lexicon Revised. Grand Rapids, 1979, p. 156). 
Si la primera pregunta busca provocar un no indignado como respuesta, la segunda acentuará más la indignación: una piedra en la mano de un hijo que pide pan parece una broma de mal gusto, pero una serpiente llega a ser una agresión por el peligro que implica.

Igualmente, no debe descartarse en estos ejemplos un recurso al humor más que a la negación enojada: dichas con una sonrisa, las preguntas podrían provocar un «ipor supuesto que no!» como respuesta, expresada con una sonrisa más amplia aún.

A su vez, pan y pescado constituyen parte de los elementos básicos de la alimentación en Galilea, y especialmente cerca del lago de Genesaret. Por otra parte, el alimento es lo más básico dentro de las necesidades de los oyentes, y el pedido no parece ir más allá de la necesidad del momento ${ }^{14}$.

Salta a la vista entonces el contraste entre los vv. 7-8, en que las promesas están absolutamente incondicionadas, respecto de los ejemplos de los vv. 9-10, en los que Jesús trata de presentar los pedidos menos exigentes y que más difícilmente se pueden negar, tanto por los elementos solicitados como por los personajes involucrados (padre-hijo).

La formulación de las preguntas, por otra parte, está fuertemente relacionada con la respuesta del v. 11 y la prepara convenientemente. En efecto, si la pretensión de Jesús fuera solo hablar de la generosidad divina en relación con los imperativos de los vv. 7-8, los ejemplos podrían no incluir la referencia a dar una respuesta tan hiriente como una piedra o una serpiente. ¿Por qué sencillamente no haber dicho: «Al hijo que les pide un pan, ustedes se lo dan»? La inclusión de una imposible respuesta hiriente acumula tensión a la ya provocada por la indeterminación de los vv. 7-8. Con razón uno puede preguntarse: ¿de qué está hablando Jesús?

\subsubsection{Argumento a minori ad maius}

El v. 11 es, entonces, clave de comprensión para entender tanto las sorprendentes promesas de la primera parte como la formulación de las preguntas retóricas de los vv. 9-10.

14 En los dos relatos de la multiplicación de los panes, la disponibilidad de los discípulos se reduce, en el primero, a «cinco panes y dos peces» (Mt 14,17) y en el segundo a «siete [panes] y unos pececillos» (Mt 15,34). Por tanto, unos pocos panes y peces conformaban la vianda básica para las recorridas con Jesús: a partir de ese mínimo será posible la multiplicación. 
Para ello, Jesús propone el argumento a minori ad maius, frecuente no solo en la práctica rabínica de su tiempo y en textos del Antiguo Testamento, sino también en su misma enseñanza ${ }^{15}$.

El recurso de Jesús a este tipo de argumentación lo emparenta sin duda con los sabios de Israel, pero también con los discursos proféticos, que no excluían tales fórmulas retóricas en la medida en que a través de ellas podían lograr el convencimiento de los oyentes.

En un número importante de los usos veterotestamentarios del argumento a minori ad maius, tanto sabios como profetas formulan consideraciones acerca del comportamiento divino o incluso del concepto de Dios que ellos tienen ${ }^{16}$. También Jesús: es que tal argumentación se muestra eficaz en cuanto el punto de partida frecuentemente propone comportamientos humanos o divinos que difícilmente pueden ser negados para afirmar con mayor contundencia aún, en el punto de llegada, lo que aún menos se pueda rechazar.

La característica propia de Jesús es que siempre usa este tipo de argumentos, al referirse a Dios o a su forma de actuación, para convencer a su auditorio del cuidado del Padre por sus hijos, y, en el caso de nuestro texto, de su disposición para dar. Esta disposición, sin embargo, y a pesar de no haber una formulación in recto acerca de cómo es el Padre, involucra también una consideración en este sentido: el texto perfectamente puede

15 En el mismo Sermón del monte, Mateo ubica varios recursos de Jesús a este tipo de argumento, siempre en textos Q: Mt 6,26 («Mirad las aves del cielo: no siembran, ni cosechan, ni recogen en graneros; y vuestro Padre celestial las alimenta. ¿No valéis vosotros más que ellas?»); 6,30 («Pues si a la hierba del campo, que hoy está y mañana se echa al horno, Dios así la viste, ¿no lo hará mucho más con vosotros, hombres de poca fe?»). En ambos casos hay incluida una declaración teológica, aunque en Mt 6,30 llamativamente se habla de Dios y no del Padre. En el resto de Mt el argumento a minori ad maius aparece en 10,25 (segundo discurso, dirigido a los misioneros) y 12,11-12 (ante los fariseos, en contexto polémico). También en las parábolas de Lc 11,5-8 y 18,2-8 se deja ver un argumento semejante (cf. J. Jeremias, Las parábolas de Jesús. Estella, Verbo Divino, 1981, p. 195).

16 Este tipo de argumentación es característico de la exégesis rabínica y está incluida entre las siete reglas de interpretación judía de la Escritura atribuidas a Hillel. Se denomina comúnmente qal wahomer o, fuera del contexto rabínico, comparación a minori ad maius: desde un dato evidente se afirma otro que se presenta como más evidente aún. Los rabinos afirman que Hillel no inventó esta regla: sencillamente se la encuentra utilizada en la Tanak: 1 Sam 14,30; 2 Sam 4,11; 1 Re 8,27; 2 Cr 32,15; Job 9,14; 15,16; 25,6; 35,14; Prov 11,31; 15,11; 17,7.26; 19,7.10; 21,27; Jr 12,5; Ez 15,5; Jdt 8,14; Sab 12,20-21; 13,3-4. Como se puede ver, si bien es frecuente en textos sapienciales, también puede formar parte de alguna oración o discurso profético y en narraciones de libros históricos. 
relacionarse entonces con la declaración de Jesús sobre la perfección del Padre (Mt 5,48), que «hace salir su sol sobre malos y buenos, y llover sobre justos e injustos» (Mt 5,45).

\subsubsection{Punto de partida humano}

En el punto de partida del argumento, Jesús asume la capacidad de los hombres para dar, aun cuando ellos son malos $^{17}$. El acento no está puesto, sin embargo, en esta maldad de los hombres, sino en su bondad. La alusión a que sus oyentes sean malvados no tiene por objeto más que profundizar la evidencia del comienzo de la argumentación.

Igualmente, el verbo sabéis caracteriza el punto de partida dotándolo de un matiz de cotidianeidad ${ }^{18}$, pero evitando, al mismo tiempo, proponer una formulación que asuma que tal conducta humana ocurra sin excepción, lo cual sería discutible y atentaría contra la evidencia del argumento.

Las dos preguntas retóricas de los vv. 9-10 son retomadas entonces por la referencia del v. 11 a los hijos. Este rasgo sitúa claramente el punto de partida en la experiencia humana constatable por el sencillo auditorio que conforman la multitud y los discípulos. Nuevamente Jesús asienta sobre base bien firme el punto de partida del argumento a minori ad maius.

17 También son malos los fariseos en Mt 12,34, con una formulación exactamente igual que en $M t 7,11$. Sin embargo, no se puede seguir de aquí que el texto de nuestra perícopa deba ser encuadrado en la polémica con los grupos farisaicos. J. Jeremias, apoyándose en la postura de A. T. Cadoux (The Parables of Jesus. Nueva York, 1931, p. 76s.), propone que nuestro texto se relaciona estrechamente con Mt 12,34: «Así, de hecho, podríamos tener en Mt 7,7-11 par. unas palabras que pudieron decirse contra malas interpretaciones de las palabras y hechos de Jesús. Como motivo habría que pensar, en primer lugar, en el escándalo habitual de los enemigos de Jesús: la predicación de la Buena Nueva a los despreciados. Los publicanos piden y son escuchados (Lc 18,13s); ¡qué escándalo! Jesús replica: “Estáis ciegos ante la bondad paternal de Dios. Pensad en vosotros y en vuestros hijos. Si vosotros, a pesar de vuestra maldad, podéis dar buenas cosas a vuestros hijos, ¿por qué no creéis que Dios es capaz de dar los dones del tiempo de la salvación a aquellos que le piden?"» (J. JeREmIAS, Las parábolas de Jesús, o. c., p. 178). De cualquier manera, no nos parece necesario ni evidente que Mt 7,7-11 no pueda ser dirigido a la multitud y a los discípulos en la medida que también ellos necesitan ser evangelizados acerca de la «bondad paternal de Dios».

18 La palabra «sabéis» (oí $\delta a \tau \varepsilon$ ) aparece otras cinco veces en el lenguaje de Jesús $(20,22.25 ; 24,42 ; 25,13 ; 26,2)$, pero solo en $M t 7,11$ con este matiz de cotidianeidad. 
Sin embargo es de destacar que el discurso no retoma el aspecto sea de engaño, sea de agresión que se descartaba en los vv. 9-10 como parte de la conducta de un padre normal. Podría haberse esperado que la prótasis de la oración condicional incluyera un inciso del tipo: «Y no perjudicáis a vuestros hijos». Tampoco parece incluirlo el punto de llegada de 7,11b.

\subsubsection{Punto de llegada: la imagen de Dios Padre}

Ante la ausencia de un inciso de este tipo, proponemos que Jesús hace referencia solapada a un aspecto de la imagen de Dios que podía perfectamente afectar a sus oyentes: ¿se preocupa Dios por nosotros? ¿Es Dios verdaderamente atento, generoso y bueno?

En este sentido, el texto de Mt 6,25-34 también parece apuntar no solo a que los oyentes no se preocupen de sus más básicos cuidados, sino a asegurar que pueden no hacerlo, porque ya el Padre se preocupa suficientemente de ellos. Para convencerlos, Jesús recurre a dos declaraciones teológicas y a parecidas formas de argumentación a minori ad maius.

Concluyendo este punto: el argumento, en su punto de llegada, alude a aquellos rasgos paternos inconcebibles, sean de engaño o de perjuicio. En

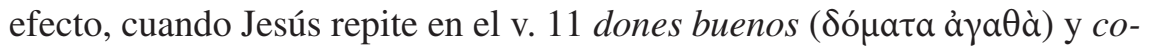
sas buenas (åja $\theta \dot{\alpha})$, está descartando ya sin nombrarlas las cosas malas a las que se aludía con la piedra o la serpiente. No hay lugar, en el pensamiento de quienes tienen que comportarse como hijos de Dios, para sospechar que Dios dé cosas malas, inútiles, engañosas o perjudiciales.

\subsubsection{Cuánto más}

Por lo demás, la clave de la argumentación a minori ad maius está en la expresión cuánto más ${ }^{19}$. Si el punto de partida ha sido sólidamente asentado en la tierra firme de la experiencia cotidiana de los oyentes y es capaz de lograr un fácil consentimiento, el punto de llegada adquiere, a través de esta fórmula, una evocación acorde con la trascendencia del Padre

19 La Biblia hebrea utiliza siempre las partículas \$ֵָ entre ambos términos de la argumentación a minori ad maius. Si bien las partículas aparecen invariables en todos los casos, es necesario recurrir al contexto para decidir la traducción en el sentido de «cuánto más»o «cuánto menos». La Septuaginta varía notablemente a la hora de traducir e interpretar los usos de 
que está en los cielos. No hay límite ni techo para afirmar la capacidad de la bondad del Padre.

El v. 11, además, completa la apertura de las promesas y constataciones iniciales. La declaración teológica, aunque respeta plenamente la trascendencia divina, afirma sin enigmas ni ambigüedades, lejos incluso de la complejidad de algunas parábolas, la disposición del Padre, de tal manera que la sorpresa que hayan podido provocar los primeros versículos encuentre ahora una razón que fundamente la seguridad y confianza a la que aquellos invitan.

Como repetía Joachim Jeremias: «Así es Dios» ${ }^{20}$. Él va a dar, él va a dejarse encontrar y va a hacer accesible su reino y su justicia, él va a abrir. Y Jesús es quien revela y convence con autoridad acerca de las intenciones bondadosas del Padre.

En el evangelio de Mateo no es este el único texto en el que el Señor aparece argumentando en este sentido. En efecto, en la parábola de los obreros de la viña, tomada del material propio del evangelista, el propietario de la viña responde a uno de los obreros que murmuran: «Pues toma lo tuyo y vete. Por mi parte, quiero dar a este último lo mismo que a ti. ¿Es que no puedo hacer con lo mío lo que quiero? ¿O va a ser tu ojo malo porque yo soy bueno?» (Mt 20,14-15). Además de algunas coincidencias de vocabulario (dar, bueno, malo) y de tema con nuestra perícopa, aparece aquí una dirección en el discurso de Jesús: su intención es convencer y revelar las bondadosas intenciones del comportamiento divino contra los límites que el pensamiento de los hombres le pueda imponer.

Desde ya que en el conjunto de la perícopa queda incluida una condición, pero ella no involucra de ningún modo al generoso dador de sus bienes, sino a los oyentes, que deben pedir, buscar y llamar.

Así entonces, la clave del texto es asegurar que esas inusitadas promesas se basan en una sabiduría de Jesús acerca del comportamiento del Padre que campea en todo el Sermón del monte. Sobre esa sabiduría se hace posible construir una experiencia de seguimiento de Jesús y de discipulado que se anime a todo: tanto a decidirse a vivir según la doctrina

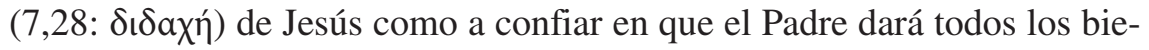
nes $(\grave{\alpha} \gamma \alpha \theta \dot{\alpha})$ necesarios para tal seguimiento.

20 J. Jeremias, Las parábolas de Jesús, o. c., pp. 167, 171, 179. A su vez, el mismo autor, en otra obra, comentará sobre nuestro texto: «El Padre de Jesús no es el Dios inamovible, inmutable, el Dios que, en última instancia, solo puede describirse por medio de negaciones, el Dios a quien es absurdo orar. No. Sino que es un Dios clemente, que escucha las oraciones y las intercesiones (Lc 13,8s; 22,31s) y que, con su misericordia, es capaz de rescindir las decisiones de su propia voluntad santa (Teología del Nuevo Testamento I, o. c., p. 169). 


\section{Lenguaje metafórico en Mt 7,7-11}

Nos proponemos ahora centrar el foco de nuestro estudio en un recurso literario que no solo hace a la forma del texto, sino también al fondo: el lenguaje metafórico. La argumentación del v. 11 invita a una profundización en esta línea. En efecto, la investigación actual acerca de la metáfora ${ }^{21}$ no se reduce a los casos en los que el análisis retórico clásico discernía una metáfora en sentido estricto ${ }^{22}$. El símil o comparación que Mateo toma de Q y que constituye una verdadera declaración teológica acerca del Padre está formulado de tal modo que es posible distinguir algunos elementos discernibles desde el análisis metafórico.

Como punto de partida aparecen dos ejemplos (vv. 9-10) tomados de la vida cotidiana familiar y englobados luego en la sentencia del v. 11a. Sobre esa base de realidades humanas se afirma algo acerca de la conducta del Padre.

La eficacia del argumento reside justamente en la evidencia de los ejemplos expresados a través de preguntas retóricas de cuya respuesta afirmativa no quedan dudas. Sin embargo, la afirmación final, que debería ser percibida como aún más evidente, en la medida en que se refiere a las realidades divinas, nos invita también a la cautela y al análisis más detenido del cambio de isotopía semántica que se ha producido.

Por otra parte, la argumentación de los vv. 9-11, y sobre todo la conclusión final (v. 11b), resuelve los enigmas de los vv. 7-8: por un lado permiten definir mejor la posibilidad de ensayar transposiciones metafóricas en la medida en que las tres binas han de referirse de un modo o de otro al Padre, que «dará cosas buenas» (v. 11) y, por otro, el escepticismo o extrañeza que pueden provocar las promesas y las seguras sentencias de Jesús, si se refieren al mundo de las relaciones humanas, no deben ya sostenerse si se refieren a Dios.

21 Para esta temática nos hemos basado en M. Dı StÉFAno (coord.), Metáforas en uso, o. c.; G. Lakoff, The Contemporary Theory of Metaphor. New York, Cambridge University Press, 1993; G. LakofF / M. Johnson, Metáforas de la vida cotidiana. Madrid, Cátedra, 1995; M. Le Guern, Sémantique de la métaphore et de la métonymie. Paris, Larousse, 1973; P. Ricoeur, La metáfora viva. Madrid, Trotta-Cristiandad, 2001; D. Bourguet, Des métaphores de Jérémie, o. c.

${ }^{22}$ A diferencia de la retórica clásica, que se preocupa en discernir la variedad de tropos del discurso, entre los que incluye como uno más la metáfora, el enfoque cognitivista considera también las comparaciones, las analogías, las alegorías y otras formas de semejanzas discursivas en cuanto manifestaciones variadas de la misma concepción metafórica del mundo propia de la condición humana. 


\subsection{Campo-fuente y campo-meta ${ }^{23}$}

El campo-fuente del símil del v. 11 está explicitado por Jesús mismo: las relaciones cotidianas de los hijos con los padres tal como se dan entre los hombres que están escuchando las palabras del Señor. Esos hombres, que no pueden enojarse de que se los trate como malos, poseen en su comportamiento una natural capacidad de dar, especialmente si es un hijo el que pide y pide cosas normales y buenas.

Nos interesa señalar que el punto de partida de la comparación importa, en cuanto al campo-fuente se refiere, un juicio, una mirada sobre los hombres que fácilmente puede universalizarse, aunque la referencia inmediata es a los oyentes de Jesús. El juicio parece ambiguo. En efecto, concede algo que muchos exigirán, sobre todo cuando se habla generalizadamente de «la gente» y no tanto de uno mismo: la gente es mala. Pero la acción atribuida a la gente que es mala habla de «saber», por lo tanto con frecuencia o con naturalidad o con ambas, «dar».

Este juicio de la gente forma parte del campo-fuente: en este se incluye no solo la experiencia común y la evidencia de la generosidad de los padres para con sus hijos, sino también un juicio innegable y compartido hasta por los más escépticos acerca de la gente. Un juicio que el reconocimiento de la maldad humana no logra impedir y que, a pesar de la concesión acerca de esa maldad, termina quitándole esa aparente ambigüedad.

\subsection{Cambio de isotropía semántica ${ }^{24}$}

La particular configuración de nuestro texto nos permite afirmar entonces que recién en el v. 11 se produce un verdadero cambio de isotopía

23 Al analizar el funcionamiento de la metáfora, la teoría cognitivista habla de «proyección metafórica». En virtud de esta última se produce una superposición de dos «campos semánticos» o dominios relacionados: el dominio-fuente, o imagen de donde procede la metáfora, y el dominio-meta, aquello que se quiere expresar metafóricamente. Ambos dominios o campos semánticos consisten en diversos elementos o casilleros que, al verse relacionados, activan una forma de conocimiento desde lo más conocido (dominio-fuente) a lo menos (dominio-meta).

24 Entendiendo isotopía como un sector de vocabulario que concierne a un tema o sujeto, el procedimiento metafórico pone en juego dos isotopías diferentes, de tal manera que el cambio de isotopías es esencial para que aquel se realice. Este cambio es el que justamente produce el asombro que ya Aristóteles había señalado como resultado de la metáfora: la realidad menos conocida es trasladada, por un lado, a un campo semántico o isotopía más accesible, pero, por otra parte, también menos esperable, lo cual provoca en el oyente la necesidad de repensar la realidad aludida desde nuevas coordenadas. Cf. D. Bourguet, Des métaphores de Jérémie, o. c., pp. 12-13: «El cambio isotópico es indispensable para que haya metáfora». 
semántica. En efecto, la conclusión a minori ad maius del v. 11 no solo remata los ejemplos de los vv. 9-10, sino que también aporta un definido campo-meta a los consejos y las afirmaciones de los vv. 7-8.

Esto significa que el procedimiento metafórico solo se hace evidente a través de este cambio final, de tal manera que se puede reconocer una interacción entre las formas literarias que han sido utilizadas: los vv. 7-8 aportan un campo-fuente de gran amplitud cuyos verbos pueden y deben relacionarse mutuamente, pero sin que se eliminen sus significados propios; los vv. 9-10 enfocan el campo-fuente en una situación humana relacionada con la primera de las tres binas, con lo cual se concentra la atención; recién el v. 11 y su conclusión permiten la llegada al campo-meta con su correspondiente cambio de isotopía semántica.

Podemos reconocer entonces un único cambio de isotopía semántica que se despliega en dos formas metafóricas: la primera, más estricta desde el punto de vista del análisis retórico clásico, identificable en la segunda y tercera bina de los vv. 7-8, y la segunda, a través de una comparación, en los vv. 9-11.

\subsection{Foco de la metáfora ${ }^{25}$}

A la pregunta respecto del foco de la metáfora debe responderse con algunas matizaciones. En la medida en que reconocemos dos formas metafóricas con un solo cambio de isotopía semántica, habría que distinguir también dos focos, aunque relacionados. A su vez, en las binas de la primera parte, el foco es de alguna manera doble, en la medida en que constan siempre de dos verbos. Sin embargo, la conclusión del v. 11 obliga a enfocarse en los segundos.

Creemos que es así en la medida en que la declaración del v. 11 aporta contenido teológico también a las expresiones de los vv. 7-8: los verbos ubicados en segundo lugar, sobre todo cuando son reforzados con el

25 «Cuando utilizamos una metáfora tenemos dos pensamientos de cosas distintas en actividad simultánea y apoyados por una sola palabra o frase, cuyo significado es una resultante de su interacción». Esta interacción permitirá no solo un crecimiento del conocimiento del dominio-meta, sino también del punto de partida de la metáfora. Una consecuencia se sigue de esto, según Black: «traducir» una metáfora buscando el término literal que se habría dejado de lado es inútil en la medida que «no consigue hacernos penetrar en la cuestión como lo hacía la metáfora» (cit. en H. DíAz, «La perspectiva cognitivista», en M. DI StéFANo (coord.), Metáforas en uso, o. c., pp. 61-62). 
adjetivo «todo» del v. 8 y expresados en tiempo presente, hablan de un comportamiento divino que es habitual.

Queda así respondido el enigma planteado por los vv. 7-8: ahora se entienden estas afirmaciones. No podrían decirse de los comportamientos humanos, pero sí de Dios: sí puede decirse que el que busca su Reino o busca hacer su voluntad encontrará al Padre dispuesto a darle esos dones; sí puede decirse que el que se anime a llamar y a clamar puede hacerlo con confianza, porque del otro lado está el Padre, que libremente responde.

En el v. 11, en cambio, el foco está determinado por la forma de la argumentación: así, no solo lo constituye el comportamiento del Padre concentrado en el verbo dar («dará cosas buenas»), sino que está potenciado por la fórmula «¡cuánto más!», propia de la conclusión a minori ad maius.

Esta fórmula nos permite una afirmación y algún cuestionamiento. Por un lado, es muy apropiada para hablar de las realidades divinas a partir de experiencias humanas: respeta la trascendencia al mismo tiempo que hace accesible la comprensión. Por otro, sin embargo, no deja de ser cuestionable desde un par de aspectos: teniendo en cuenta la imagen veterotestamentaria de Dios (¡escasamente invocado como Padre!) ${ }^{26}$, ¿es tan evidente para esos hombres el «icuánto más!»? Además, ¿quién podría afirmar con autoridad algo relacionado con la conducta divina habitual?

Anotemos por ahora: respecto del primer cuestionamiento, debe señalarse que Jesús justamente elabora todo el argumento en función de la persuasión de un público que, en principio, no está necesariamente dispuesto a aceptar la conclusión a la que se llega. Respecto del segundo, solo se entiende la convicción de Jesús desde las declaraciones de Mt 11,25-27. Aquí él no parte de los datos del Antiguo Testamento: él es el revelador del Padre, y este rasgo de su mensaje sin duda formó parte de aquel asombro y admiración de la gente que los evangelios nos han hecho llegar.

26 En cuanto a la denominación «Padre» aplicada a Dios y la correlativa de hijo o hijos para Israel o los hombres en general, es sabida la escasa utilización del motivo en el Antiguo Testamento. No debe extrañar que sea así, en la medida en que el concepto de padre, al acentuar los aspectos biológicos de la relación con Dios, no podía sino atentar contra la trascendencia propia de la fe veterotestamentaria, más allá de su amplia utilización en los mitos de las religiones contemporáneas a Israel. Para

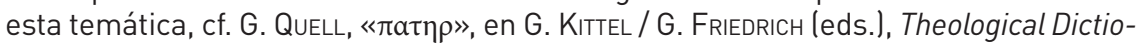
nary of the New Testament IV. Grand Rapids, Eerdmans, 1977, pp. 965-969. 


\subsection{Entonación del discurso ${ }^{27}$}

En los estudios recientes acerca de los procedimientos metafóricos debe notarse la importancia que puede adquirir la entonación de un argumento o sentencia con elementos metafóricos incluidos en el discurso. En efecto, la entonación puede alterar significativamente el alcance de la metáfora, lo cual obliga a investigar detenidamente si se puede percibir y de qué manera afecta al texto.

Tratándose de las perícopas evangélicas, en la medida en que constituyen documentos con origen en la tradición oral basada en las palabras del Señor, pero sobrecargada a veces por tradiciones comunitarias de las primeras Iglesias a lo largo de varias décadas, el discernimiento de alguna forma de entonación podría apoyarse sobre bases demasiado endebles.

Sin embargo, nos parece que es posible intentar alguna aproximación a la entonación de las palabras del Señor en nuestro texto, sobre todo considerando que la transmisión a partir del Documento Q tanto en Mt como en Lc es muy concordante.

\subsection{Recurso a la ironía}

Así entonces proponemos que la base de la argumentación final del v. 11 ( «Si, pues, vosotros, siendo malos, sabéis dar dones buenos a vuestros hijos»), lejos de ser una consideración con pretensiones propias de la antropología filosófica o teológica, es una afirmación cargada de ironía e incluso de cierto humor.

Humor irónico, porque la afirmación de la maldad humana de los oyentes va unida a la evidente capacidad de ser generosos y buenos, con lo cual se relativiza seriamente la primera afirmación.

Esta propuesta se corresponde y refuerza al considerar la afirmación final del mismo v. 11 («¡cuánto más vuestro Padre que está en los cielos dará bienes a los que se lo piden!»): ella participa del tono irónico y humorístico de tal manera que adquiere su contundencia argumentativa gracias a ese tono.

27 «La entonación puede tener un lugar decisivo en la interpretación de una metáfora; en efecto, el sentido de una metáfora puede cambiar totalmente de acuerdo a la entonación con la cual se ha dicho; el tono irónico puede hacer decir lo contrario de las palabras escuchadas; las mímicas del orador pueden amplificar o aminorar el sentido...» (D. Bourguet, Des métaphores de Jérémie, o. c., p. 11). 
Es cierto que, si bien el carácter irónico e incluso humorístico es propio del tono del discurso, sin embargo el efecto que provoca para la argumentación es verdaderamente serio. En efecto, lo que está en juego es el centro del mensaje de Jesús: la revelación del Padre. Aquí está hablando aquel que ha dicho: «... ni al Padre lo conoce bien nadie sino el Hijo, y aquel a quien el Hijo se lo quiera revelar» (Mt 11,27). En nuestro texto no solo queda involucrada la imagen del Padre, sino la capacidad del Hijo para revelar esa verdadera imagen a los «pequeños» (Mt 11,25) que lo escuchan.

El procedimiento ha sido partir de la realidad de los oyentes a través de los ejemplos de los vv. 9-10, un campo-fuente extremadamente accesible y evidente, para llegar a una afirmación acerca de la conducta del Padre, campo-meta del que Jesús se presenta entonces como único testigo autorizado.

Existe, sin embargo, una diferencia: el campo-fuente es definido y concreto en cuanto señala acciones bien determinadas con objetos precisos. En cuanto al campo-meta se refiere, las palabras de Jesús se generalizan convenientemente a través del plural «bienes» (v. 11) y, en cuanto a su valor, intensidad y aun cantidad, se pierde toda determinación respecto de los máximos por medio de la promesa del «cuánto más» del mismo v. 11.

Partiendo de estas consideraciones podemos decir que la formulación, perfectamente accesible para cualquier auditorio, permite, a través de un procedimiento de tono irónico-humorístico, afirmar como absolutamente innegable lo que, planteado con la seriedad de una formulación teológica, podría perder eficacia. No es lo mismo decir: «Por lo menos Dios es tan bueno como nosotros», que decir: «Dios es la suma bondad», o algo semejante.

En orden a enriquecer el análisis creemos oportuno señalar que el mismo procedimiento irónico con un efecto de tremenda seriedad se encuentra en un autor cuasi contemporáneo nuestro. Charles Péguy, en $E l$ misterio de los Santos Inocentes, hace afirmar a Dios mismo, con gran eficacia argumentativa: «Soy un hombre honrado», «yo soy un buen cristiano» ${ }^{28}$.

${ }^{28}$ Ch. PÉguy, El misterio de los Santos Inocentes, o. c., p. 26. Conviene citar el contexto, cargado siempre de la misma ironía:

«No me gusta, dice Dios, el que desconfía de mí.

Creéis que me voy a divertir jugándoos malas pasadas, como un rey bárbaro.

Creéis que dedico mi vida a tenderos trampas y a disfrutar viéndoos caer en ellas.

Yo soy un hombre honrado, dice Dios, y actúo siempre con rectitud.

Yo soy el honor, y la rectitud, y la honestidad.

Soy un buen francés, dice Dios, recto como un francés.

Leal como un francés.

Soy el rey de Francia, recto como el rey de Francia. 
Tales expresiones ${ }^{29}$ son, desde el análisis retórico clásico, más claramente metafóricas que en la comparación del texto evangélico. A través de estas breves fórmulas, a más de encontrar un semejante recurso irónicohumorístico, se puede reconocer también la referencia a la experiencia de los oyentes-lectores, seguramente «buenos cristianos», o sedicentes «honrados», o que al menos saben lo que eso significa. Dicho de otro modo, para hablar de un campo-meta determinado (la imagen de Dios) se ha convocado a un campo-fuente semejante y a una entonación similar.

\section{Consecuencias para la exégesis del texto}

\subsection{La imagen de Dios involucrada}

A partir de estas constataciones en torno a la entonación del argumento del v. 11, y aun de toda la perícopa, conviene volver la mirada a un singular uso veterotestamentario de la argumentación a minori ad maius.

Creemos encontrar en el final del libro de Jonás un antecedente de nuestro texto en cuanto a algunos elementos estilísticos y temáticos. En efecto, cerrando la discusión en torno al ricino entre el profeta y YHWH, este último afirma, paradójicamente, con una negación que debe traducirse como pregunta:

Lo que el último de los pobres no hubiera temido de san Luis, ¿vais a temerlo de mí?

En fin, ¡yo valgo quizá tanto como san Luis!

Creéis que me voy a divertir haciéndoos fintas como un espadachín.

Toda la malicia que tengo es la malicia de mi gracia, y la finta y el engaño de mi gracia, que con tanta frecuencia actúa con el pecador para su salvación, para impedirle que peque.

Que seduce al pecador, para salvarle. Pero acaso creéis. Creéis que yo, Dios, me voy a divertir causándoles dificultades y portándome como no haría un hombre honrado. Yo soy un buen cristiano, dice Dios. Creéis que me voy a divertir sorprendiéndoles como un asesino nocturno» (ibid.).

29 Por solo sumar otra referencia de interés en la literatura universal citamos una metáfora de Shakespeare, que, como suele pasar con los parlamentos de sus personajes humorísticos, no deja de tener seriedad. Para el alguacil Dogberry, en un texto lleno de non-sense, Dios es un buen hombre («God's a good man») (W. ShaKeSPEARE, Much Ado About Nothing III, 5). El contexto invita a entender la expresión en el mismo sentido de los textos analizados de Mt y Péguy: lo menos que se puede decir de Dios es justamente eso, que su generosidad tiene un piso mínimo en la generosidad humana. 


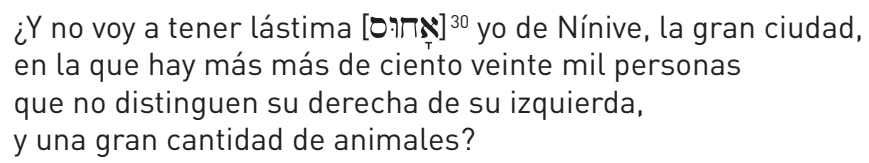

La frase rezuma ironía: frente a la mezquina e innegable compasión o preocupación de Jonás por su árbol, el autor del librito afirma la más innegable todavía compasión de YHWH por las miríadas de gentes de Nínive, y, ya que el profeta es tan considerado con un vegetal, también se afirma que la compasión de YHWH alcanza a «una gran cantidad de animales» (v. 11).

En este breve texto hay también un argumento a minori ad maius

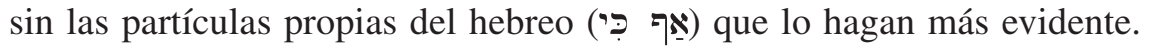
También está presente el punto de partida humano, consignado con ambigüedad: la demostrada mezquindad de Jonás no le impide compasión. Desde ese punto de partida se afirma un aspecto del actuar divino en relación con los hombres. Y, por último, a la falta de medida de la expresión mateana puede compararse la incondicionada expresión del libro de Jonás respecto de la misericordia divina con las multitudes, a las que no se caracteriza más que con una particularidad puramente negativa («no distinguen su derecha de su izquierda») y que, por tanto, permite incluir a toda la humanidad.

Por tanto, en Jonás, como en nuestro texto, la pregunta que subyace se refiere a la imagen que tanto el ficticio Jonás como los oyentes de Jesús y los lectores de ambos textos tenemos de Dios: ¿es posible que pensemos tan mal de él? ¿Es posible que sospechemos que Dios no tenga ni siquiera la preocupación que Jonás tuvo por su efímero arbolito o que los padres comunes tienen por sus hijos o, al decir de Péguy, lo que a un «buen cristiano» le corresponde?

Proponemos, entonces, que estas preguntas que parafrasean el texto de Mt 7,11 apuntan a desbaratar las sospechas y dudas respecto de las intenciones divinas que pueden anidar en el corazón de los oyentes del Sermón del monte. Y nuevamente recurrimos a un aspecto de los recientes estudios acerca de la metáfora: nos referimos a la relación que se establece entre el campo-fuente y el campo-meta y que es posible discernir en cada procedimiento metafórico.

30 Solo una vez se afirma en el AT que Dios tiene piedad usando esta raíz (Ez 20,17: «Pero tuve una mirada de piedad para no exterminarlos, y no acabé con ellos en el desierto»). Sin embargo, el autor de Jonás quizá recuerda mejor las repetidas veces en las que en el mismo libro de Ezequiel se niega esa compasión: Ez 5,11; $7,4.9 ; 8,18 ; 9,5.10 ; 24,14$. Además, la misma negación aparece en Jr 13,14. 


\subsection{Un campo-meta problemático}

En efecto, el campo-fuente de las comparaciones de los vv. 9-11 es presentado, como ya hemos visto, como absolutamente evidente. Así, Jesús propone las relaciones entre padres e hijos no como algo abstracto, sino apelando a la experiencia de sus oyentes (vv. 9-10: «¿Acaso hay alguno entre ustedes...?») y contando siempre con una respuesta claramente afirmativa.

El campo-meta, como también se ha dicho, es, para los oyentes, sin duda menos conocido: el trascendente y misterioso mundo de las decisiones divinas. En la consideración tanto de oyentes como de lectores de todos los tiempos, ese campo meta es, en virtud precisamente de su inaccesibilidad, muy pasible de ser invadido por la sospecha y las dudas: ¿puede querer Dios el bien de todos, incluso de los paganos, que apenas distinguen su mano izquierda de la derecha? ¿No tiene Dios incontables requisitos para que alguien pueda pedirle algo con la confianza de recibirlo? ¿No se esconde Dios, con demasiada frecuencia, de los que lo buscan? ¿A qué alturas morales y espirituales hay que llegar para animarse a golpear las puertas del cielo?

El campo-meta es, en realidad, intensamente problemático: desde casi la primera página de la Escritura, la sospecha abre una brecha entre Dios y sus hijos que no existe entre los sencillos hombres que escuchan a Jesús en relación con los suyos. Así es como la serpiente seduce a Adán y Eva, tergiversando las consignas de YHWH y atribuyéndole unas intenciones ajenas a las que el mismo YHWH ha manifestado (Gn 3,1-5; cf. 2,16-17).

La sospecha o duda acerca de la intención divina de otorgar sus dones buenos al hombre caracteriza así desde siempre las complejas relaciones entre Dios y su creatura: el texto del Génesis es punto de partida para que la pregunta sobre la disponibilidad y capacidad divina para pensar y hacer el bien del hombre se vea sobrecargada, sea por la insistencia de los autores sagrados en la lejanía y santidad de Dios, sea por el furor del Dios «hombre de guerra» en los combates de $\mathrm{YHWH}^{31}$, sea por el repetido

31 El cántico de Moisés (Ex 15,1-18) recurre a una metáfora para caracterizar al

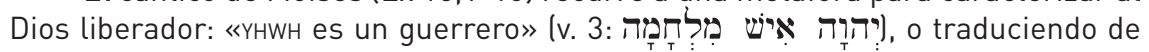
modo literal: «YHWH es un hombre de guerra». La fuerza de la metáfora reside en su simplicidad y conviene a la euforia de la gesta victoriosa. La Biblia de Jerusalén², fuera de este caso, traduce esta expresión por «hombre(s) de guerra»: así para Maquir (Jos 17,1), los hombres de Israel (Jue 20,17), Goliat (1 Sam 17,33), David (2 Sam 17,8) y los ejércitos de Gog $(E z 39,20)$. Estremece encontrar a YHWH en la compañía de tales «hombres de guerra». La Septuaginta cambia el signo de la desafo- 
fracaso de su pueblo amado, sea por el escepticismo y realismo de no pocos sabios, sea por el casi siempre mudo testimonio de los enemigos del pueblo de Dios, sea por las quejas de los relegados por la elección divina.

\subsection{Autoridad de Jesús}

Jesús sabe bien todo esto y por eso asombra y sorprende a través del argumento centrado en el «cuánto más» del v. 11. Él quiere trasladar la claridad serena y cotidiana que emana de las comparaciones de los vv. 9-10 a las problemáticas relaciones entre Dios y los hombres. Más todavía, sus oyentes deberían asumir que esa claridad es aún mayor. Ni siquiera señala un límite: lo deja abierto. La referencia al «Padre que está en los cielos» nos da la medida, es decir, infinita.

Si los procedimientos metafóricos nos permiten, entre otros logros, iluminar un aspecto de la realidad haciéndolo accesible a nuestro conocimiento, aquí hay un ejemplo de ello. Sin embargo, no debe dejarse de lado una característica de la eficacia del discurso de Jesús: él recurre de alguna manera a la experiencia común, al sentido común, y este recurso es parte de su capacidad de convicción, que llevará al auditorio (y a la comunidad creyente de Mt) a convenir en el «asombro» y la «autoridad» (cf. 7,28-29) del Señor.

Por otra parte es Jesús también quien bendice al Padre por haber «revelado a los pequeños» «estas cosas» $(11,25-26)$. Su capacidad de convicción y su autoridad provienen también, entonces, de su conciencia de ser el único revelador del Padre.

Por tanto, no basta tener en cuenta la precisa elección de Jesús de un determinado campo-fuente para hablar de las realidades divinas. Como ya hemos señalado, hay que contar también, aun cuando se corra el riesgo de perder seguridad en el análisis, con las implicaciones que se siguen de la entonación del discurso o parte del mismo. Como hay que contar no solo con la capacidad de convicción de los argumentos utilizados, sino con la autoridad con la que se expresan.

Señalemos finalmente que, en relación a estos últimos aspectos, hoy percibimos a través del testimonio de los evangelios una referencia aparen-

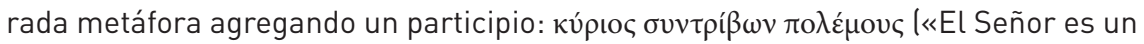
Dios quebrantador de guerras»; la expresión se repite en el canto de Jdt 16,2). En el hebreo, incluso redobla su fuerza en la medida en que el dístico de estructura quiástica (guerrero-YHWH-ҮHWH-nombre) se completa con la referencia a su nombre: tan esencial como su nombre es su condición de guerrero... 
temente circular: Jesús convence desde el sentido común, la gente se asombra por su autoridad, Jesús bendice porque los pequeños reciben la revelación, él es el único que puede darla. Desde aquí, nosotros percibimos el elemento de «autoridad» de Jesús, aquel elemento que rompe la circularidad en el foco de la metáfora: solo quien tiene la autoridad de ser el único revelador del Padre nos puede convencer al hablar del mundo divino presentándonos como más evidente lo que de por sí no necesariamente lo es.

\section{Conclusión}

Mt 7,7-11 habla de la oración, sin ninguna duda, pero no solo, ni siquiera principalmente. Para entender las prioridades de esta pequeña parte de la doctrina de Jesús habría que empezar por el final. Porque justamente el último versículo, el v. 11, es el que, como un sol, ilumina los anchos campos que se han abierto en las primeras sentencias.

Jesús quiere hablarnos allí del Padre. Sin duda es su Padre, el «que está en los cielos», el mismo YHWH que tanto habla y del que tanto se habla en la Ley y los Profetas. El Dios que está más allá de toda fantasía o imagen humana, más allá de la plena comprensión de quienes lo adoran, lo sirven y también lo niegan.

Ese Padre, sin embargo, se parece más a los hombres de lo que ellos mismos sospechan. $\mathrm{O}$, mejor dicho, tiene más semejanzas con la sencilla humanidad que no cree necesitar reconocimiento cada vez que, con gesto simple, pone el pan en la mesa familiar.

El problema está en que a esos mismos hombres y mujeres, atentos a la necesidad de sus hijos, no se les pase por la cabeza que haya un Dios que participe de sus mismas preocupaciones cotidianas; que sea un Dios que escucha, aunque siga siendo soberano; que no se esconde, aunque esté más allá de todo; que sale a abrir la puerta, aunque le sobren sirvientes y su mansión sea inexpugnable.

Era necesaria tal revelación cuando va cayendo el sol en la tarde del Sermón del monte: ¿cómo podrían los oyentes animarse a algo si tuvieran que edificar una nueva fidelidad a Dios sobre las palabras de ese pobre rabino campestre que parece hablarles solo de imposibles? Pero no: él ha sido tan astuto como para evocar esas elementales bondades humanas, esas en las que ellos ni se fijan, para convencerlos de las elementales bondades divinas.

Si es así, entonces él habla de conductas realmente posibles. Posibles no porque sean fáciles o convenientes, sino porque son propias del 
Padre perfecto que espera hijos perfectos. Y de aquí posibles, porque el $\mathrm{Pa}-$ dre perfecto al menos es tan innegablemente atento con sus hijos como ellos lo son con los suyos.

El sol ya está en lo más alto cuando Jesús pronuncia «¡cuánto más!». Su astucia es máxima porque ha acercado al Padre hasta comprenderlo desde la bondad humana para después alejarlo, pero solo en cuanto a esa misma capacidad bondadosa.

¿Queda así algún lugar para la sospecha? Ahora los oyentes son trasladados de su lugar de dadores del pan al de hijos pequeños sentados a la mesa: ¿cabe en el niño alguna duda acerca de las intenciones de la madre y del padre? ¿Puede pensar mal y atribuirles intenciones de perjuicio o daño? Hasta ese nivel de infantil confianza nos lleva Jesús: a sentarnos a la mesa familiar de cada comunidad cristiana, después de una semana de jugar, revolcarnos, ensuciarnos y pelearnos, para tomar el pan bueno y el pescado sabroso que el Padre sirve sin pretender más que la alegría de que sus hijos terminen pareciéndose a él. Si eso pasa en nuestras familias, ¿cuánto más en la de él?

¡Cuánto más! ¡Cuánto más! Hay que repetirlo incansablemente. No son muchas las oportunidades en que nos sentimos plenos, o cercanamente a ello, por un gesto de solidaridad, de austeridad, de rectitud, de honestidad, de fidelidad, de lucidez, de sinceridad. Cada una de esas experiencias es una ventana para conocer y tocar al Padre: ¡cuánto más será el Padre que nosotros en cada una de sus capacidades! El Padre se nos da a conocer tanto en la respuesta a nuestros golpes a su puerta como en aquellos dones que él mismo da: cada don suyo nos acerca a su perfección y nos habla de sus perfecciones. No hay don suyo que escape a ello.

Todos ellos son pasibles del ¡cuánto más! Todo cuanto pueda ser contado como «dones buenos». Incluso nuestra capacidad de indulgencia, débiles como somos. De paciencia, pobres como somos. De alegría, sufridos como somos.

Juan Carlos Roldán p_jcroldan@yahoo.com.ar 